\title{
Editorial
}

\section{Managing brand performance: Aligning positioning, execution and experience}

Journal of Brand Management (2010) 17, 465-471. doi:10.1057/bm.2010.11

\section{THE COMPELLING NEED FOR BRAND ALIGNMENT}

The traditional thinking is that brands are built through marketing investments such as communications and advertising. Although advertising is a tool of brand building it is over-weighted in its importance to delivering an exceptional brand. Exceptional brands are delivered through brand alignment, of which advertising may be a component or in some cases may be absent altogether. Google is one of the most recognized brands in the world. It is ranked at number seven (higher is more valuable) on Interbrand's Best Global Brands 2009. Yet, do you recall ever seeing a Google advertisement on television, radio or print? CEO Eric Schmidt has stated that Google's dominant market share is because of quality of searches and not advertising. ${ }^{1}$

To deliver a strong brand experience for customers the organization needs to develop strong internal alignment with the brand among internal stakeholders and resources, and strong external alignment with external stakeholders, partners, customers and consumers.

We call this the alignment of brand visionaries, brand providers and brand believers (see Figure 1). Brand visionaries are managers who set the brand strategy in motion. They are concerned with making promises of value propositions to the customer. This focus demands customer intimacy to understand customer needs and self-reflection to understand company and partner capabilities. Brand visionaries are also in charge of specifying what will be done for the brand providers, which include employees, channel partners and franchisees. The role of brand visionaries is to help facilitate the promises about the brand providers' role in enabling and facilitating promises about value propositions to customers. Brand providers are in charge of how the brand is delivered. Frontline staff and delivery channels are responsible for the interactive co-creation of meaning and experience that embodies the value propositions of the brand. Operational excellence insures this interactive marketing consistently delivers on the brand promise. In the following sections we will discuss the good, the bad and the ugly of brand alignment and the effect on brand promises.

\section{THE INTERNAL LIFE OF THE BRAND}

In every organization thousands of decisions are made on a daily basis. It is, practically speaking, impossible for the executive management to micromanage all of these decisions. A strong brand provides a consistent way to polarize multiple microdecisions, so they reinforce each other in a way that is synergistic. Southwest Airlines 


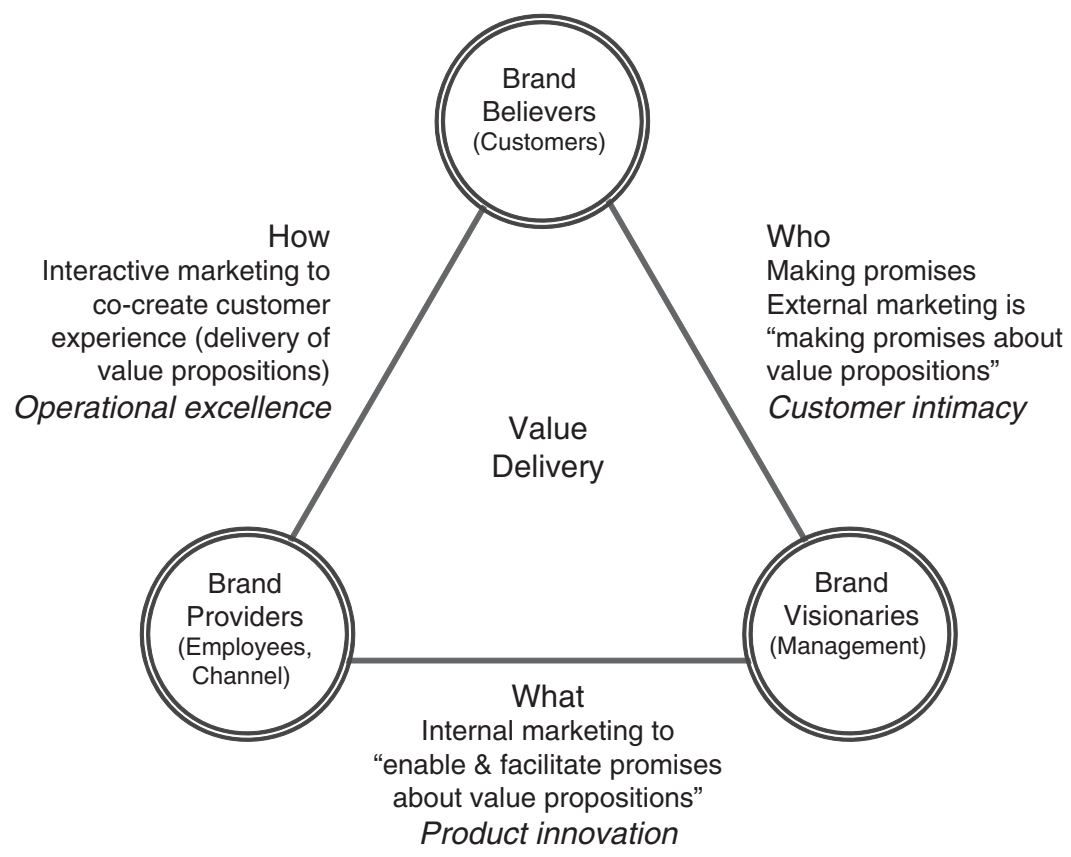

Figure I: Brand alignment framework.

has a simple mantra of being the low-cost competitor. When Herb Kelleher, the former CEO, was onboard his decisionmaking guidance was simple. If someone came to him recommending that Southwest Airlines develop a program to recognize the birthdays of its customers he would retort that if the initiative would support making Southwest the lowest-priced competitor on the market that logic would decide whether to pursue the idea. A simple stated strategy is one that is also easy to follow for brand providers.

The brand reward system needs to reflect the value of the brand to align goals and metrics. Southwest not only made sure the minds of the employees were guided by strategy; it also made sure their pocketbooks were aligned with strategy. In 1974, it initiated the first profit-sharing plan in the US airline industry. When the employees own the company stock it is in their best interest to create future value for the company.

Front-line employees are brand ambassadors. They represent the brand and can bring it to life for the customer beyond what is possible with media communications, by making it personal. This concept of brand ambassador is essentially a role for management in aligning employees within the corporation. Managers need to build a vision of company strategy. They also need to bring that strategy to life by building a company culture that embodies the essence of that strategy. By going one step further, by using the concept of train-the-trainer, companies can educate a few talented individuals within the company and position them to drive the brand values throughout their areas of influence within the firm.

Apple's foray into retail brought some innovations to light regarding how it delivers its customer service. One aspect of that customer service is the Genius Bar that is staffed by Genii. Newly hired Apple Genii go to Apple's headquarters in Cupertino for 2 weeks of intensive training where they earn Apple technical certifications and learn the minutiae of AppleCare internal policies. Apple advertises its career 
opportunity for Genii as 'To delight. Enrich. Impress. Engage. Inspire.' and screens its job candidates for those 'having passion about customer service and a commitment to exceeding expectations'. ${ }^{2}$ Its hiring is aligned with its brand promise as Apple's customer satisfaction score is at 84 with its closest rival, Dell, trailing at $74 .^{3}$ There are some compromises in the system, such as the Genii are trained mostly for current products, and therefore legacy products do not get much support, and unlike Dell with its 24-hour turnaround time Apple does not guarantee service turnaround times, which can be a huge hassle for individuals with only one computer. ${ }^{4}$ But for many of Apple's fanatics it is a small price to pay to be a part of the club.

In addition to the Genius Bar, Apple also offers free workshops in many of its stores on using Apple hardware and applications. The Pro Lab series offers free sessions to learn applications like Aperture, Logic Pro and Final Cut Pro. The Apple stores' One to One training offers a year of weekly training for just US\$99 per year. At that price the value seems quite unbeatable. Apple efforts do not go unrewarded at the cash register. Its stores, on average, bring in over $\$ 23$ million per year at estimated sales per square foot at $\$ 4000$, as compared with Best Buy's \$930, Neiman Marcus' $\$ 611$ and luxury store Tiffany \& Co.'s $\$ 2666 . .^{5}$ Apple brings it all together where the brand promise to the brand believers and the brand providers are as one.

Great brands consistently renew their brand culture. In 2008, Starbucks recognized its quality was deteriorating. ${ }^{6}$ Howard D. Schultz, its CEO, bemoaned the "watering down' of the Starbucks experience. There was a lot of coffee confusion behind the counter as too many times when a cappuccino was ordered what was served would have been called a latte as it was filled to the brim with milk. To address this issue Starbucks shut down 7100 of its stores to implement a company-wide retraining effort. ${ }^{7}$ Customers were turned away at the door while the baristas inside the store were led on a back-to-basics boot camp. One would think that the 'coffee taste and flavor' would be paramount in importance for customer satisfaction yet higher ranked than this is 'friendly staff' and 'treatment as a valuable customer'. A smile launches happiness, and Starbucks realizes it needs to focus on soft skills.

The best companies measure their employee's intellectual and emotional engagement with the brand. Company culture is aligned to the brand in a similar fashion where any brand campaign aligns the brand promise with the value proposition for consumers. Employees need to know what the brand promise is all about and what the value proposition is for them to deliver on that brand promise. In this context it is critical to ensure 'quick recovery' from negative brand experiences owing to service failures. The best way to handle service quality mishaps is to work them out of the system. This is the strategy for Singapore Airlines, which is recognized worldwide for its excellent service. The company runs an academy where all staff are retrained on a regular basis and cabin crew are evaluated at least four times a year to ensure the brand is delivered with integrity across normal service processes and special situation handling. The Singapore Airlines staff always appear quite engaged in delivering the best possible service. A way to gauge employee engagement is to view it through the framework of Csikzentmihalyi where people act with 'flow' for their work. ${ }^{8}$ Flow is a mental state where a person is fully involved in their activity with an energized focus. It is described as an innately positive experience because it makes use of skills for optimal performance. Flow is correlated with a higher motivation to perform and perform well. ${ }^{9}$ Brand engagement assessment needs to go a 
step further and measure an employee's knowledge, beliefs and attitudes towards the brand.

Consistency across the brand portfolio is a necessary element of strong brand strategy. Samsung has risen to a path to quality across its brand portfolio. Not only does it produce stellar televisions and personal electronics but it is also rated number one by JD Power on home appliances including refrigerators, clothes washers and clothes dryers. ${ }^{10}$ It is important for the brand to guide and represent a specific level of quality to deliver across the portfolio and, in addition, it is important to continuously support the quality over time. Canon is a solid example of this in cameras. Its cameras are consistently rated highly by expert reviewers. Canon delivers on this by having made a commitment to achieving the best in optics across its wide product portfolio of cameras, copiers, projectors, scanners, eyecare, freespace optics and motion pictures equipment. Brand consistency is driven by a strong brand vision to guide what the brand providers are to deliver.

Brand vision also helps guide decisions over product lifecycles. Apple also has been a good sequencing value from Mac to iPod to iPhone to iPad. By establishing consistency over the portfolio the new brands launched not only are supported by the legacy brands, but the legacy brands are revived and revitalized by the new brands. In this down economy, one of the few bright spots is Apple, whose sales have continued to climb, and the company claims 9 out of every 10 dollars spent for computers over the $\$ 1000$ price point. In the first quarter of 2008 it only claimed 6.6 dollars of every 10 dollars spent. ${ }^{11}$ The call to brand consistency across the brand portfolio helps employees know what to strive for in the new generation of products.

Google's Nexus One phone provides a good illustration of how a lack of internal focus on the customer value proposition can lead things astray. Google developed a software platform called Android that it licenses to hardware manufacturers including HTC, Motorola, Samsung and Sony. ${ }^{12}$ In December 2009, Motorola launched the Droid phone based on Android 2.0 on the Verizon network to a frenzy of sales reaching a million units sold faster than the iPhone. After this great success Google announced on 5 January 2010 that it would launch its own phone called the Nexus One. However, unlike the Motorola Droid the Nexus One tripped on its way off the starting block. Its hardware was top notch but its software was overhyped. It contained Android 2.1, which was a minor upgrade and less than what the customers expected. But the biggest hurdles were not based on the product. The phone was originally sold exclusively on T-Mobile that trails in markets share at 12 per cent compared to Verizon and AT\&T at 31.1 per cent and 25.2 per cent, respectively. ${ }^{13}$ Subsequently, the phone was made available on the AT\&T network but it was sold only in an unlocked version at $\$ 530$, which places it at a very hefty premium over the $\$ 199$ iPhone that is sold locked and subsidized by the carrier. The final slip-up was that Google was not ready for prime time as a consumer electronics company as its customer service was greatly lacking. Users found it hard to connect with a real human to handle service support and the response time for service requests was dismal, taking several days turnaround on emailed questions. The result was tepid sales with the Google Nexus One gaining only 2 per cent in market share by the end of Q1 2010 of Android phones. A company expanding its portfolio from a product oriented to a service or solution orientation needs to retool at a deeper level to understand what will drive the overall value for the customer. The expected promise at the customer level needs to be aligned with brand providers' delivery of the brand. 
Strong brands align their external promises to their internal operations. Southwest Airlines, as a low-cost provider, has aligned its activities with its strategy. It offers limited passenger service with no meals, no seat assignments, no connections with other airlines and no baggage transfers. It has frequent reliable departures made possible by 15-min gate turnarounds, automatic ticketing machines and highly productive grounds crew who are motivated through high compensation, and stock ownership. The union contract is flexible, benefiting the airline. In addition, the costs are controlled by limited use of travel agents, standardized 737 aircraft, high asset utilization and service via point-to-point routes between mid-sized cities and secondary airports for larger urban airports. The competitive advantage does not come from one activity but rather the holistic group of interlocking activities. ${ }^{14}$

As the saying goes, the greatest compliment is imitation. Delta launched a wholly owned budget carrier Song Airlines and intended to copy Southwest's model by offering limited in-flight catering, single aircraft type, higher asset utilization, improved staff utilization and reduced channel costs. ${ }^{15}$ Although the changes improved Song's cost by $20-30$ per cent over Delta, it was still short of the 28 per cent and 39 per cent costs advantage over Delta by JetBlue and Southwest. ${ }^{16}$ Song's strategy was caught in the middle with compromises it had to make as a subsidiary of Delta including having to participate in Delta's expensive pilot contract, negotiating schedules, routes and pricing with Delta, and recruiting cabin crew from Delta's furloughed employees. At an estimated cost of launching Song at $\$ 65$ million, it was an expensive experiment to make. James Whitehurst, the COO of Delta at the time, is quoted as saying it was 'very expensive' to support two brands, and given Delta was undergoing bankruptcy proceedings it was forced to shut down Song. ${ }^{17}$ The problem with imitation is if you do not get all the interlocking activities right you are bound for a competitive disadvantage. To make things work for radical innovation a company needs to manage its businesses more like independent portfolios or else the dominant culture will crush the fledgling before it can take wing.

\section{EXTERNAL ALIGNMENT OF THE BRAND}

Brands need to be aligned to markets and for developed world companies there is a tendency to overinvest in mature markets and underinvest in emerging markets. Big American automakers General Motors and Ford totally missed the bottom of the market. Ford especially is out of touch with its heritage as the Model $\mathrm{T}$ is generally regarded as the first affordable car. Tata Motors is at the vanguard of the new emerging market of new car buyers and its Nano car priced at $\$ 2000$ it is being called the world's cheapest car. Months before the release of the first model in 2009 Tata Motors stated there was already a waiting list of 203000 people who have placed orders for the car and a wait until 2011. ${ }^{18}$ Ford can count that as a missed opportunity.

BP is in the middle of a crisis of one of the biggest man-made disasters ever. The BP website states 'We help the world meet its growing need for heat, light and mobility, and strive to do so by producing energy that is affordable, secure and doesn't damage the environment'. The company used to be known as British Petroleum that it castoff for a catchy 'Beyond Petroleum' tags. Greenpeace had already pointed out in 2008 that this tag was but a farce with 93 per cent of the companies investment tied up in petroleum and the remainder 2.79 per cent in wind, 1.39 in solar and 2.79 per cent in biofuels. ${ }^{19}$ The oil leak in the 
Gulf of Mexico is currently spewing an estimated 210000 gallons of oil a day and an estimated four million gallons in total has leaked to date. Any goodwill BP had built up with its investment in advertising is flowing out the door. The risks of oil drilling includes disasters, but the technologies to mitigate a disaster should not be 'new and untried' as it is said 'the first rule is - don't make things worse' than they already are. ${ }^{20}$ Clearly, the promise to customers by $\mathrm{BP}$ is misaligned with its internal priorities.

Companies also need to align to pulses in the market. Big shows like the Consumer Electronics Show are important for many companies to make major announcements. However, Apple is bucking the trend on this one. The MacWorld Expo held every year in January in San Francisco has been anchored by Apple. ${ }^{21}$ In 2008 it was announced that Apple would no longer provide a keynote address at the show as the firm decided tradeshows had become a minor part in reaching the customer, given the increasing popularity of the retails stores that handle 3.5 million visitors a week. Nonetheless, tradeshows are of great importance in many industries as they consolidate the buyers for a big sales push.

\section{BRINGING IT ALL TOGETHER}

What have we learned from this array of examples on brand alignment? For internal branding the company must align its people, resources and operations. The most important asset for a company is its employees, who need to be fully engaged to deliver on the brand promise. The company culture is the leader of the brand as it guides decisions for the staff. Appointing brand ambassadors to lead the company culture is a way of institutionalizing the brand throughout the organization. And the engagement of the people needs to be tracked to ensure the delivery of the brand matches the internal partners. This can be accomplished with focusing on best practices in measuring brand engagement.

For optimal internal alignment of resource the brand visionaries need engender attention to the price/value ratio of their offers across the portfolio and over time. Consistency in value delivered helps brand providers understand the value targets and helps the customers understand the brand positioning. The best companies explore the most effective ways to build a brand that balances both to current sources of revenue and to future value.

Companies need to pay attention to aligning strategy and execution. There are different needs for structuring around radical versus incremental innovation so companies need to pay attention to their structures to make things work. Imitation is the highest form of flattery, however if one element is in misalignment it can throw out the entire value proposition. Companies need to align their external promises to their internal operations to a high level of detail. Activity mapping can help understand if your strategy is different and how to make it different. Companies consistently need to revisit their activity maps as they need to realign across the product life cycle from innovation to efficiency.

Delivery of strong brands does not take place in a vacuum. Brand partners need to be aligned to deliver on the brand promise. And brands need to be aligned with pulses in the market. The buying cycles for certain industries, like skiing, is drastic and in other industries there may be not seasonal factors but rather artificial timing elements like tradeshows, or complimentary product release cycles.

As we see from the examples management that align the 'who', 'what' and the 'how' of brand delivery are amply rewarded. Although this is part science and part arts, those who master the triangle of brand alignment stand triumphant in the eyes of their shareholders, customers and partners. 


\section{REFERENCES}

(1) Goldman, D. (2010) Super bowl ad breaks Google's TV silence. CNNMoney, 8 February, http://is $. \mathrm{gd} / \mathrm{c} 5 \mathrm{fYy}$.

(2) Apple Inc. (2010) Apple genius job description, http://is.gd/c3BCE, accessed 12 May 2010.

(3) ACSI. (2010) ACSI computer industry satisfaction index, http://is.gd/c3zWE, accessed 12 May 2010.

(4) Robinson, E. (2007) Exclusive: A day in the life of an Apple genius. MacLife 28 May, http://is.gd/c8PQk.

(5) Martin, S. (2006) How apple stores beat tiffany. Red Herring 18 December, http://is.gd/c3zZ2.

(6) Eng, M. (2008) Starbucks closing 7000 plus stores - For several hours - To train baristas. Chicago Tribune, http://is.gd/c3zOn.

(7) Grynbaum, M.M. (2008) Starbucks takes a 3 hour coffee break. New York Times, http://is.gd/c3zSV.

(8) Csíkszentmihályi, M. (1996) Creativity: Flow and the Psychology of Discovery and Invention. New York: Harper Perennial.

(9) Csíkszentmihályi, M., Abuhamdeh, S. and Nakamura, J. (2005) Flow. In: A.J. Elliot (ed.) Handbook of Competence and Motivation. New York: The Guilford Press.

(10) JDPower.com. (2010) http://is.gd/c3A3L, accessed 12 May 2010.

(11) Apple Wilcox, J. (2009) Apple has 91 per cent of market for $\$ 1000+$ PCs, says NPD, http://is.gd/ c3zVj, accessed 12 May 2010.

(12) Nosowitz, D. (2010) The fast rise and fall of the Nexus One, the tragic 'Google phone'. Fast Company 10 May, http://is.gd/c3HZV.
(13) comScore. (2010) comScore reports March 2010 US mobile subscriber market share, http://is.gd/ c3Oy3, accessed 12 May 2010.

(14) Porter, M. (1996) What is strategy? Harvard Business Review: 61-78, http://is.gd/c5die.

(15) Rivkin, J.W. and Therivel, L. (2004) Delta Air Lines (B): The Launch of Song. Boston, MA, USA: Harvard Business Case Harvard Business Press.

(16) JetBlue and Southwest.

(17) Maynard, M. (2005) Delta to discontinue its low-fare song airline. New York Times 28 October, http://is.gd/c3ZCy.

(18) Tata Kurczewski, N. (2009) Tata Nano: 200000 orders and a waiting list through 2011, http:// is. $\mathrm{gd} / \mathrm{c} 4 \mathrm{hZu}$, accessed 12 May 2010.

(19) Jamie (2008) BP wins coveted 'Emerald Paintbrush' award for worst greenwash of 2008, http:// is.gd/c3PVd, accessed 12 May 2010.

(20) Vergano, D. (2010) BP pursues short-term ways to stop leak. USA Today 12 May, http://is.gd/ c3Qid.

(21) Dowling, S. (2008) Apple announces its last year at MacWorld, 16 December, http://is.gd/c4iKN, accessed 12 May 2010.

Rajendra K. Srivastava and Gregory M. Thomas Singapore Management University, Singapore E-mail: gmthomas@smu.edu.sg 